\title{
Eimeria falciformis BayerHaberkorn1970 and novel wild derived isolates from house mice: differences in parasite lifecycle, pathogenicity and host immune reactions
}

\author{
Al-khlifeh, E. ${ }^{1,2}$; Balard, A. ${ }^{1,2}$; Jarquín-Díaz V.H. ${ }^{1,2}$; Weyrich, A. ${ }^{3}$; Wibbelt, G. ${ }^{4}$; Heitlinger, E ${ }^{1,2}$. \\ ${ }^{1}$ Research Group Ecology and Evolution of molecular Parasite-Host Interactions, Leibniz Institute for \\ Zoo and Wildlife Research, Alfred-Kowalke-Straße 17, 10315 Berlin, Germany. \\ ${ }^{2}$ Humboldt University, Institute for Biology, Dept. Molecular Parasitology, Philippstraße 13, 10115 \\ Berlin, Germany. \\ ${ }^{3}$ Department Evolutionary Genetics, Leibniz Institute for Zoo and Wildlife Research, Alfred-Kowalke- \\ Straße 17, 10315 Berlin, Germany. \\ ${ }^{3}$ Department Wildlife Diseases, Leibniz Institute for Zoo and Wildlife Research, Alfred-Kowalke- \\ Straße 17, 10315 Berlin, Germany.
}

\begin{abstract}
Species of Eimeria (Apicomplexa:Coccidia) differ in the timing of lifecycle progression and resulting infections vary in host immune reactions and pathology they induce. Eimeria infections in house mice are used as models for basic immunology and the most commonly used isolates have been passaged in laboratory mice for over 50 years. We questioned in how far such isolates are still representative for infections in natural systems.

In the current study, we address this question by comparing the "laboratory isolate" E. falciformis BayerHaberkorn1970 with a novel, wild derived isolate E. falciformis Brandenburg88, and contrast this with another novel wild derived isolate, E. ferrisi Brandenburg64. We compare parasite lifecycle progression. We relate this to immune cell infiltration at the site of infection (in the caecum) and cytokine gene expression in the spleen as a measure of host immune response. We assess host weight loss as a measure of pathogenicity.
\end{abstract}

A species-specific slower parasite lifecyle progression and higher pathogenicity are observed for $E$. falciformis vs. E. ferrisi. Host cytokines, in contrast, are expressed at significantly higher level in the 
spleen of mice infected with the E. falciformis laboratory isolate than in both wild derived isolates, irrespective of the species. Differences in histopathology are observable between all three isolates: The E. falciformis BayerHaberkorn1970 laboratory isolate induces the strongest inflammation and cellular infiltration (with lymphocytes, plasma cells and eosinophilic granulocytes) followed by the wild derived E. falciformis Brandenburg88 isolate. E. ferrisi Brandenburg64 is inducing milder histological changes than both E. falciformis isolates.

It can be speculated that the serial passaging of E. falciformis BayerHaberkorn1970 has resulted in evolutionary divergence rendering this isolate more virulent in NMRI mice. Caution is needed when findings from experimental infection with laboratory strains should be integrated with observations in natural systems.

\section{Highlights}

- E. ferrisi has a shorter pre-patency than wild-derived and laboratory isolates of E. falciformis.

- E. ferrisi is less virulent than both E. falciformis isolates and the timing of maximal oocyst shedding relative to host weight loss differs.

- The laboratory strain of E. falciformis induces stronger cytokine expression in the spleen than both wild derived strains of E. falciformis and E. ferrisi.

- The laboratory strain of E. falciformis induces stronger tissue infiltration of immune cells than the wild-derived strain. E. ferrisi infections are associated with the lowest infiltration.

Keywords: wild-derived strains; laboratory evolution; house mouse; rodent Eimeria; cytokine expression; immune cell infiltration.

\section{Introduction}

Maintenance of parasite lifecycles via serial passaging is a cornerstone of experimental parasitology. Parasites are propagated under defined and controlled conditions with the aim to provide infective stages for experiments (Lucius et al., 2017). The procedure allows the parasite to evolve due to mutation and genetic drift or adaptation to the passaging host and environment (Ebert, 1998; Burke, 
2012). Genetic drift is promoted by the use of small inocula during passaging, and drift can act while diversity of a parasite isolate is reduced intentionally to obtain a clonal strain. In clonal strains mutation and drift can continue to act (Farrell et al., 2014). Considering adaptive evolution, an important part of the passaging environment is given by living hosts (Elena and Lenski, 2003), which usually have low genetic diversity (e.g., clonal or inbred lines, cultures), are immunologically naive due to the absence of previous infections (Mackinnon and Read 2004) and lack co-infections with other parasites (Abolins et al., 2017). Procedures for serial passaging of parasites typically collect infective stages at a particular time after infection and use the obtained inoculum to infect new animals or use haphazard infections in dense environments. Iteration of such a static routine likely differs from natural parasite environments with different timing of infections and variable transmission. In most cases both the biotic (host) and abiotic (outer environment) during passaging differs profoundly from the environment experienced by the parasite during its life cycle under natural conditions. To summarize, parasite laboratory isolates might experience both neutral and adaptive evolutionary processes. As a consequence they might not be representative for analogues in natural systems.

Serial passage leads in most cases to higher virulence (enhanced growth and reproduction of the parasite, and larger impact on the host) in the host type used for the process (reviewed by Ebert, 1998). This can be due to low genetic diversity in host populations (for example inbred lines) used for passage, reducing fitness trade-offs associated with specialization and promoting the expansion of more virulent pathogens. This phenomenon has been demonstrated in systems including the apicomplexan parasites Plasmodium spp. in rodents (Mackinnon and Read, 1999, 2004; Barclay et al., 2014). Adaptation to the passage host in these studies increases parasite virulence.

Contrary, but still consistent with this, passage of highly virulent isolates of the apicomplexan parasite Eimeria spp. can lead to attenuation of virulence when only the first oocystes committing to sexual reproductions are selected (McDonald and Ballingall 1983; Shirley and Bellatti 1988; Matsubayashi et al., 2016). These attenuated strains are called “precocious lines” and are the basis for live vaccines used in the poultry industry (Shirley and Long, 1990). Given the practical implications of this phenomenon, numerous experiments focused on changes in parasite life history, virulence and host response that arise as a consequence of attenuation. It is clear from these experiments that Eimeria spp. respond quickly to selection pressure. In contrast - to our knowledge - no studies attempt to correlate enhanced virulence after serial passaging of Eimeria with physiological (e.g. immune-) responses in the passaging host. 
Species of the genus Eimeria usually have a small host range, often infecting a single host species (Hnida and Duszynski, 1999; Kvičerová and Hypša, 2013; Hashimoto et al., 2014; Vrba and Pakandl, 2015) and reside at specific sites within the intestines of their hosts (Haberkorn, 1970; Owen, 1975; Chapman et al., 2013). All species have a direct life cycle with asexual expansion and sexual reproduction within epithelial cells of the gastrointestinal tract before transmission stages (oocysts) are released. Diploid oocysts become infective after reductive divisions (sporulation) in the environment (Canning and Anwar, 1968).

Eimeria spp. are widespread in diverse host species including many vertebrates from mammals to fish (Molnár et al., 2012). Infection causes damage in the intestinal mucosa resulting in malabsorption of nutrients and weight loss (Haberkorn, 1970; Chapman et al., 2013). As this has an economic impact in livestock, coccidiosis is an important focus in veterinary research (Brake et al., 1997; Laurent et al., 2001; Gadde et al., 2009; Swaggerty et al., 2011). Eimeria species capable of natural infection of the house mouse (Mus musculus) have been proposed as a model for e.g. host immune response against Eimeria (Heitlinger et al., 2014; Schmid et al., 2014). Serial passaging of laboratory isolates of Eimeria is usually conducted by collecting oocysts at the day of peak shedding. Oocysts are sporulated in an aqueous solution of potassium dichromate and inocula are used for new infections two to six months later, before infectivity decreases. The isolate E. falciformis BayerHaberkorn1970 has been isolated in 1960 (Haberkorn 1970) and since has been propagated in laboratories (first at Bayer animal health, Monheim, Germany; then at the institute for molecular parasitology of the Humboldt University, Berlin, Germany). In nearly 60 years since its isolation E. falciformis BayerHaberkorn1970 has likely become the most commonly used laboratory isolate of rodent Eimeria (Mahrt and Shi 1988; Schito et al., 1996; Steinfelder et al., 2005; Pogonka et al., 2010; Stange et al., 2012; Schmid et al., 2014, 2012; Ehret et al., 2017).

In the present study we compared infection of mice (NMRI) with the laboratory isolate E. falciformis BayerHaberkorn1970, to infections with wild derived isolates of E. falciformis (novel isolate Brandenburg88) and E. ferrisi (Levine and Evens, 1965) (novel isolate Brandenburg64). We assessed similarities and differences in proliferation of tissue stages, oocyst shedding and in the host pathological changes and immune response between the three different Eimeria isolates. 


\section{RESULTS}

\section{Dynamics of infection and host body weight loss differ between Eimeria species}

Genotyping showed that two novel isolates which we obtained from individual house mice captured in the federal state of Brandenburg (Germany) belong to the species E. falciformis and E. ferrisi. We compared fragments of DNA sequences of the mitochondrial Cytochrom C oxidase subunit I (COI), the nuclear small ribosomal subunit (18S) and the open reading frame 470 (ORF470) of the apicoplast genome. For all makers the Brandenburg88 and Brandenburg64 isolate showed 99-100\% sequence identity to available sequences from E. falciformis and E. ferrisi, respectively. This identifies the isolates robustly as the respective species as described before (Jarquín-Díaz et al., 2019). We named the novel isolates E. falciformis Brandenburg88 and E. ferrisi Brandenburg64 after the area (Brandenburg) from which they were isolated and a running number for mice used in our sampling (mouse no. 64 and 88).

We infected NMRI mice with these novel Eimeria isolates as well as with the laboratory isolate E. falciformis BayerHaberkorn1970 and followed the progression of infection by measuring parasite reproduction and host body weight loss. We assessed parasite reproduction via oocyst shedding from two to eleven days post infection (dpi) (Figure 1a). The two E. falciformis isolates and E. ferrisi showed different infection dynamics in NMRI mice: oocyst shedding of E. ferrisi has its peak intensity at 6 dpi, was drastically reduced at $7 \mathrm{dpi}(\mathrm{n}=12, \mathrm{U}=2.91, \mathrm{p}=0.002)$, and fell below detection levels at 10 dpi. Oocyst shedding of E. falciformis has a peak intensity at 8 dpi for the laboratory isolate BayerHaberkorn1970 and at 9 dpi for the novel isolate Brandenburg88. The oocyst numbers declined after this peak in both isolates, but shedding was still detectable at $11 \mathrm{dpi}$ when we sacrificed the last mice. For the two E. falciformis isolates we observed no difference in shedding intensity of oocysts at the peak day ( $\mathrm{n}=12, \mathrm{U}=0.24, \mathrm{p}=0.846)$ and peak oocyst abundance did not differ significantly between E. ferrisi and both E. falciformis strains (E. ferrisi vs. E. falciformis Brandenburg88, $\mathrm{n}=12, \mathrm{U}$ $=0.32, \mathrm{p}=0.777$; E. ferrisi vs. E. falciformis BayerHaberkorn1970, $\mathrm{n}=12, \mathrm{U}=0.96, \mathrm{p}=0.37$ ).

The period of patency (oocyst shedding) was characterized by body weight loss in infected mice in all infections (Figure 1b). Infections with E. ferrisi coincided with significant weight loss at 4 dpi $(\mathrm{n}=18$, $\mathrm{U}=-2.43, \mathrm{p}=0.013)$ and $5 \mathrm{dpi}(\mathrm{n}=18, \mathrm{U}=-2.52, \mathrm{p}=0.010)$ in comparison to the control group. Infection with E. falciformis was accompanied by significant weight loss at 8 and 9 dpi in both $E$. falciformis BayerHaberkorn1970 (both dpi, $\mathrm{n}=12, \mathrm{U}=-2.89, \mathrm{p}=0.002$ ) and E. falciformis Brandenburg88 (8dpi, $\mathrm{n}=12, \mathrm{U}=-2.41, \mathrm{p}=0.013$; 9dpi, $\mathrm{n}=12, \mathrm{U}=-2.89, \mathrm{p}=0.002$ ) isolates as 
compared to the control group. Weight losses in infections with E. ferrisi at their maximum (at 5 dpi) were, however, significantly lower compared to weight loss in infections with E. falciformis at their maximum (9 dpi; E. ferrisi vs. E. falciformis Brandenburg88, $\mathrm{n}=15, \mathrm{U}=-2.0, \mathrm{p}=0.049$; E. ferrisi vs. E. falciformis BayerHaberkorn1970, $\mathrm{n}=15, \mathrm{U}=-2.59, \mathrm{p}=0.007)$.

Oocyst shedding and weight loss show different relative timing in E. falciformis compared to E. ferrisi. In infections with both isolates of E. falciformis weight loss coincides with or follows up to two days after oocyst shedding. In infections with E. ferrisi weight loss precedes peak oocyst shedding by one day or more (Figure 2).

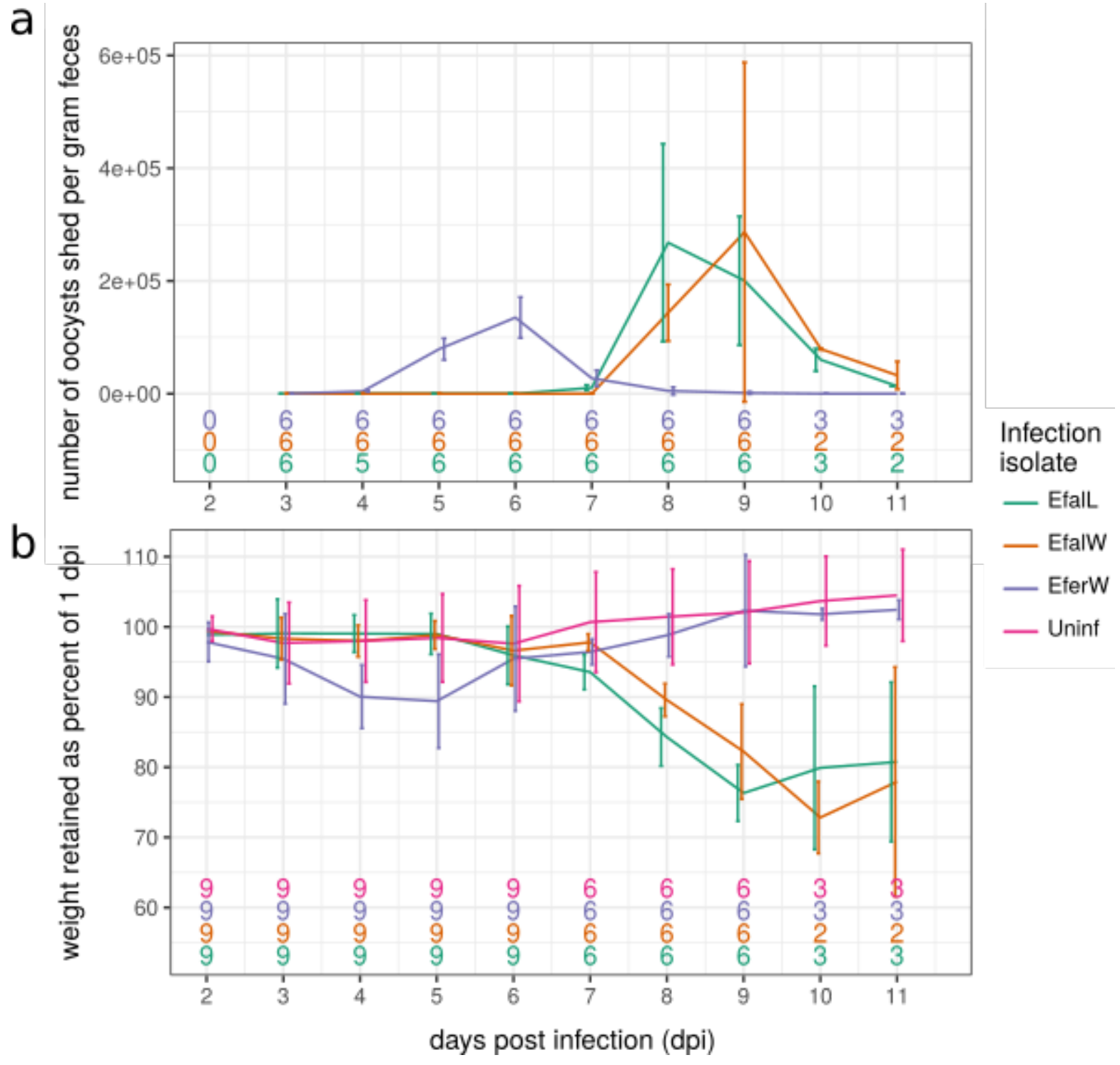


Figure 1 - Parasite life cycle progression and pathogenicity assessed as host weight loss during the infection - Dynamics of parasite reproduction and host weight loss differ between the species $E$. falciformis and E. ferrisi. a) Oocyst shedding of Eimeria spp. from experimentally infected mice (NMRI) is displayed from 1 to 11 days post infection (dpi). Mice were infected with 200 sporulated oocyst of E. ferrisi Brandenburg64 (a recently derived isolate; EferW), E. falciformis BayerHaberkorn1970 (a classical laboratory isolate; EfalL) or and E. falciformis Brandenburg88 (a recently derived isolate, EfalW). b) Host body weight loss of the same three groups of mice is depicted as percentage of body weight retained compared to $1 \mathrm{dpi}$. The number of mice per group is given at the bottom of the plot. The number is gradually reduced towards the end of the experiment, because mice were sacrificed for collection of tissue samples. Lines indicate the mean for each group, error bars give the standard deviation.
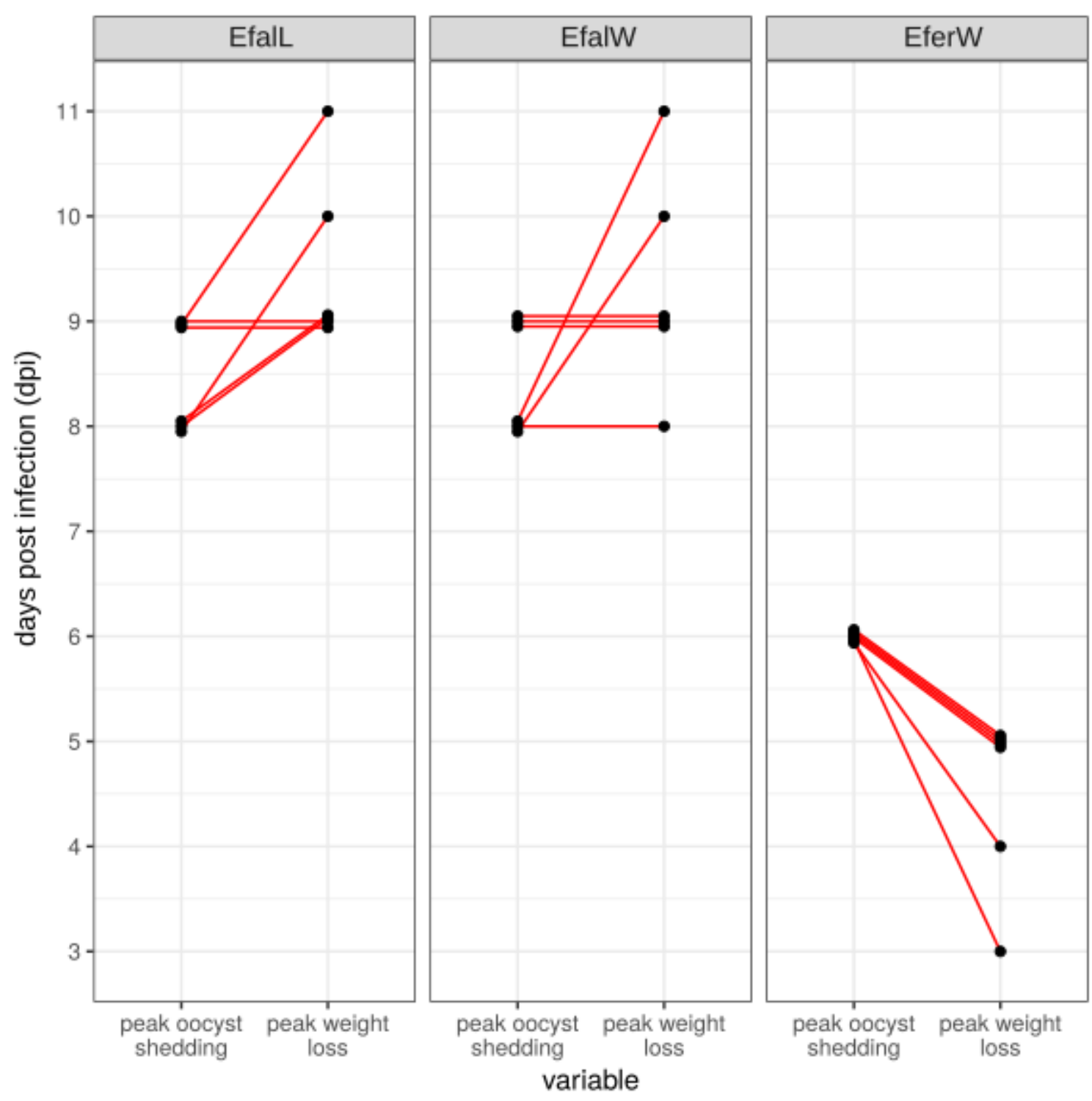
Figure 2 - Relative timing of host weight loss and parasite reproduction differ between the species $\boldsymbol{E}$. falciformis and $\boldsymbol{E}$. ferrisi for individual hosts - The peak of the host's weight loss follows after the peak of oocyst shedding in infections with E. falciformis, while in infections with E. ferrisi the hosts lost most weight before most parasite oocysts were shed. Points depict the peak day of both oocyst shedding and weight loss, respectively, red lines connect both measurement from the same mouse. All mice sacrificed at 9dpi or later are assessed. For underlying experimental procedures see Figure 1 and the Methods section. In case of E. falciformis infections the day of maximal weight loss could have been potentially even later if some mice ( $\mathrm{n}=3$ for each isolate) were not sacrificed at 9 dpi.

\section{Intensity of tissue stages of Eimeria spp.}

Eimeria infections in our study result in a transient presence of parasite stages in epithelial cells of the caecum. We quantified the intensity of infection by a quantitative PCR (qPCR) assay using gDNA from caecal tissue. By specifically amplifying genes for the parasite (Cytochrome C-oxidase subunit I; COI) and the host (nuclear $c d c 42$ gene), we analysed the ratio of parasite DNA to host DNA. We report this ratio on a native (log2) scale of measurement and further refer to it as host-parasite $\Delta \mathrm{Ct}$ (Figure 3 ). The analysis of infected (E. ferrisi $\mathrm{n}=15$; E. falciformis Brandenburg88 $\mathrm{n}=14$; E. falciformis BayerHaberkorn1970 $n=14)$ and control samples $(n=13)$ allows us to estimate a limit of detection (LOD; mean + 2 standard deviations of the negative controls) for the assay at a host-parasite $\Delta \mathrm{Ct}$ of 3.73. This corresponds to eight Eimeria COI molecules for 100 copies of the mouse nuclear genome. We measured the highest value for an individual negative control sample at a host-parasite $\Delta \mathrm{Ct}$ of 4.84. Maximum values for host-parasite $\Delta \mathrm{Ct}$ (observed for the E. falciformis BayerHaberkorn1970 isolate) were 7.74, indicating a ratio of 214 parasite COI mDNA copies for each copy of the mouse genome in crude caecum tissue at this point.

At 3 dpi E. ferrisi has the highest value of host-parasite $\Delta \mathrm{Ct}$ (6.19), while most infections with $E$. falciformis were still below the limit of detection (all E. falciformis Brandenburg88 and for two out of three E. falciformis BayerHaberkorn1970). For E. falciformis (both isolates) host-parasite $\Delta \mathrm{Ct}$ increased to values well above zero (equal numbers of parasite mitochondrial and host nuclear DNA copies) at $5 \mathrm{dpi}$ and highest values were reached at $7 \mathrm{dpi}$. Again, the amount of DNA measured for $E$. falciformis (at this peak intensity) was similar to that of E. ferrisi (at $3 \mathrm{dpi}$, its peak). At 11 dpi the parasite-mouse $\Delta \mathrm{Ct}$ was reduced to values below zero for all samples, and for most samples below the limit of detection (except for one E. ferrisi sample, for which a value of 3.86 was measured). 


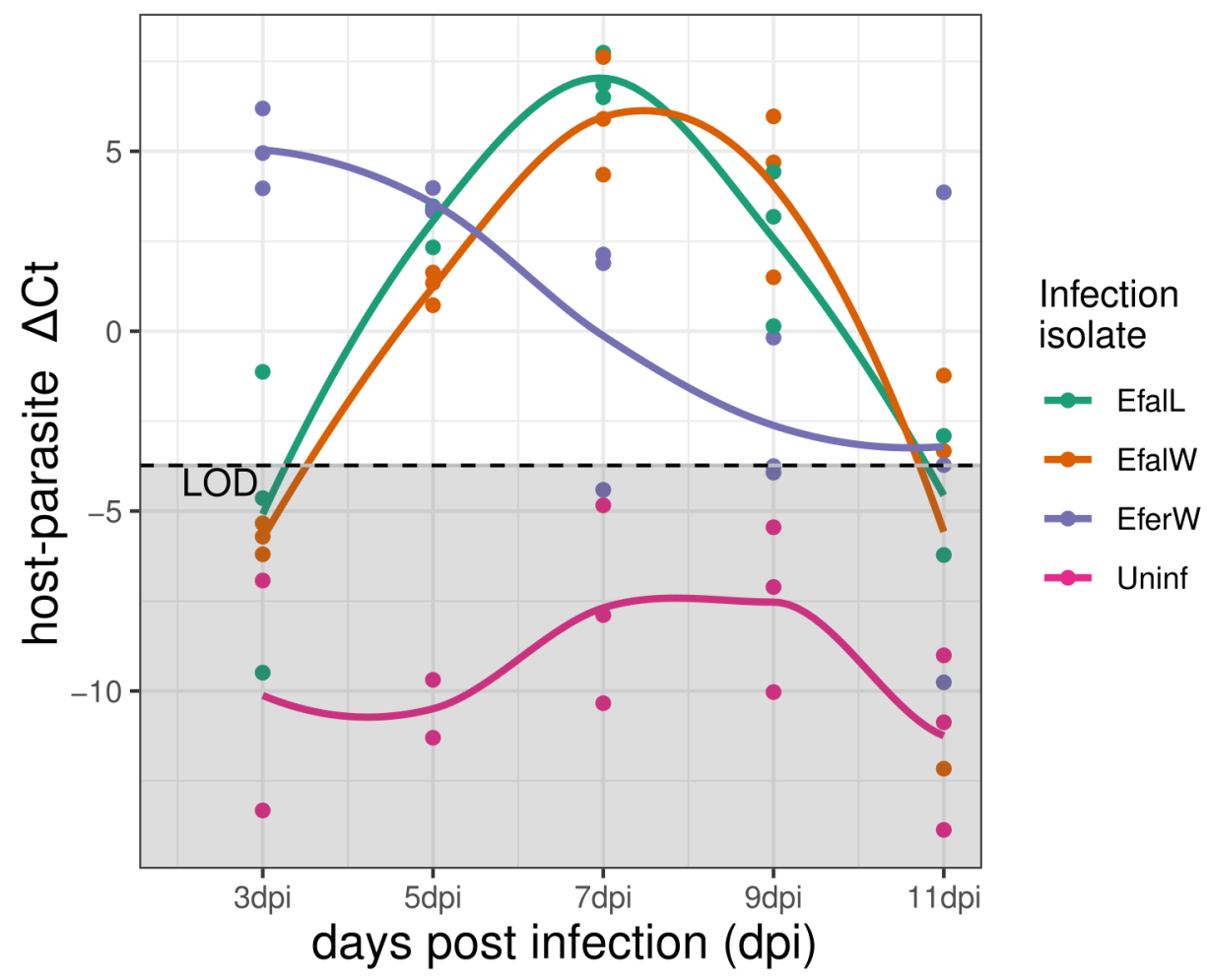

Figure 3 - The relative amount of parasite vs. host DNA (host-parasite $\Delta C$ t) estimates the intensity of parasite stages in caecum tissue. The host-parasite $\Delta \mathrm{Ct}$ was calculated from the difference in cycle of threshold (Ct) values of qPCRs performed on a single copy nuclear gene (Cdc42) of the host and on a mitochondrial (COI) gene of the parasite. A limit of detection (LOD) was calculated as the mean +2 standard deviations of $\Delta \mathrm{Ct}$ values of the negative controls. Coloured lines are drawn using local polynomial regression fitting (a "loess smoother").

\section{Differences in immune gene expression between the laboratory and wild-derived isolates}

To characterize potential differences in the immune response of NMRI mice against the Eimeria isolates we assessed gene expression of relevant cytokines in the spleen. Expression levels for most genes differ significantly between uninfected controls and mice infected with the laboratory isolate $E$. falciformis BayerHaberkorn1970 (Figure 4). We used linear mixed effect models with dpi as random effect to "pool” information over multiple dpi, effectively increasing sample sizes (Table 1). Mice infected with E. falciformis BayerHaberkorn1970 show significantly higher expression levels of chemokine 9 (CxCl9), interleukins 10 and 12 (Il10 and Il12), tumour growth factor beta (Tgf $\beta$ ), and signal transducer and activator of transcription 6 (Stat6). We did not detect significant expression 
differences between control and E. falciformis BayerHaberkorn1970 infected mice for interleukin 6 (Il6) and interferon gamma (Ifny).

In contrast, for both wild-derived strains, E. falciformis Brandenburg88 and E. ferrisi Brandenburg64, expression levels for any of the examined genes do not differ significantly between uninfected and infected mice. Expression levels in infections with the laboratory isolate are significantly elevated also compared to infections with both wild derived parasite isolates (Table 1).

Some genes show (according to the model outlined above) non-significant differences in gene expression profiles over the negative control for the whole course of infection. This includes differences between infections with different parasite isolates (Figure 4). We did not analyse these differences on individual days statistically due to the low sample sizes, but give a description of our observations. Il6 shows elevated levels of expression for all infection groups compared to controls at 5 dpi. Expression levels for Ifny seem elevated only at 5 dpi and only in infections with the E. falciformis BayerHaberkorn1970. Both cases of potential elevations in expression fail to be detected as significant over controls in our mixed effect models, likely because they are transient and diminished already at 7 dpi. Il10, Il12, Stat6 and CxCl9 show elevated expression levels at multiple days of infection with E. falciformis BayerHaberkorn1970 compared to all other infection groups (and were thus significant in our model). Tgfß shows elevated expression levels early in infection with E. ferrisi (3 and 5 dpi) and late in infections with E. falciformis BayerHaberkorn (7 and 9 dpi). Taken together these observations add detail on the individual cytokines and underline our general finding of differences between wildderived and laboratory isolates of E. falciformis.

In summary host gene expression of genes relevant for immune responses does not differ significantly from uninfected controls during infection with wild derived isolates of both E. falciformis and E. ferrisi. In contrast, most genes are expressed at significantly higher levels in infections with the laboratory isolate of E. falciformis BayerHaberkorn1970 compared to uninfected controls but also to all other infections including those with the wild derived E. falciformis Brandenburg88 isolate. 


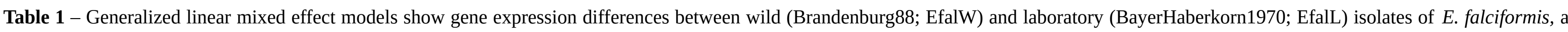
wild-derived isolate of E. ferrisi (Brandenburg64) and uninfected controls (Uninf).

\begin{tabular}{|c|c|c|c|c|c|c|c|c|c|c|c|c|c|c|c|c|c|c|c|c|c|}
\hline & \multicolumn{3}{|c|}{ CXCL9 } & \multicolumn{3}{|c|}{ Il10 } & \multicolumn{3}{|c|}{ Il12 } & \multicolumn{3}{|c|}{ Il6 } & \multicolumn{3}{|c|}{ Infy } & \multicolumn{3}{|c|}{ Stat6 } & \multicolumn{3}{|c|}{$\operatorname{Tgf\beta }$} \\
\hline & $B$ & $C I$ & $p$ & $B$ & $C I$ & $p$ & $B$ & $C I$ & $p$ & $B$ & $C I$ & $p$ & $B$ & $C I$ & $p$ & $B$ & $C I$ & $p$ & $B$ & $C I$ & $p$ \\
\hline \multicolumn{22}{|c|}{ Fixed Parts: Contrast against uninfected (intercept) } \\
\hline (Intercept) & 0.39 & $-0.15-0.92$ & .194 & 0.04 & $0.01-0.07$ & .012 & 0.01 & $0.00-0.01$ & .035 & 0.13 & $0.00-0.26$ & .087 & 0.04 & $-0.05-0.14$ & .400 & 0.07 & $0.01-0.13$ & .045 & 1.11 & $0.61-1.60$ & $<.001$ \\
\hline inf.strain (EfalL) & 0.87 & $0.38-1.36$ & .001 & 0.06 & $0.03-0.08$ & $<.001$ & 0.01 & $0.00-0.02$ & $<.001$ & 0.03 & $-0.06-0.13$ & .499 & 0.08 & $-0.04-0.20$ & .194 & 0.13 & $0.06-0.21$ & $<.001$ & 0.81 & $0.14-1.48$ & .021 \\
\hline inf.strain (EfalW) & 0.24 & $-0.25-0.73$ & .334 & -0.00 & $-0.03-0.03$ & .918 & 0.00 & $-0.00-0.01$ & .606 & 0.08 & $-0.02-0.17$ & .109 & 0.00 & $-0.12-0.13$ & .955 & 0.03 & $-0.04-0.11$ & .380 & 0.24 & $-0.43-0.91$ & .480 \\
\hline inf.strain (EferW) & 0.10 & $-0.38-0.58$ & .694 & 0.01 & $-0.01-0.04$ & .374 & 0.00 & $-0.00-0.01$ & .403 & 0.02 & $-0.08-0.11$ & .721 & 0.06 & $-0.06-0.18$ & .353 & 0.02 & $-0.05-0.09$ & .622 & 0.61 & $-0.04-1.27$ & .074 \\
\hline \multicolumn{22}{|c|}{ 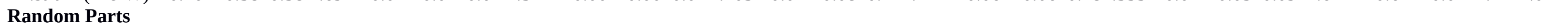 } \\
\hline$\sigma^{2}$ & & 0.437 & & & 0.001 & & & 0.000 & & & 0.016 & & & 0.027 & & & 0.010 & & & 0.814 & \\
\hline T00, dpi.diss & & 0.216 & & & 0.000 & & & 0.000 & & & 0.015 & & & 0.003 & & & 0.002 & & & 0.028 & \\
\hline $\mathrm{N}_{\text {dpi.diss }}$ & & 5 & & & 5 & & & 5 & & & 5 & & & 5 & & & 5 & & & 5 & \\
\hline ICC $_{\text {dpi.diss }}$ & & 0.331 & & & 0.227 & & & 0.270 & & & 0.478 & & & 0.084 & & & 0.140 & & & 0.033 & \\
\hline Observations & & 57 & & & 57 & & & 57 & & & 57 & & & 57 & & & 57 & & & 57 & \\
\hline $\mathrm{R}^{2} / \Omega_{0}^{2}$ & & $.456 / .453$ & & & $.440 / .437$ & & & $.421 / .417$ & & & $.498 / .495$ & & & $.162 / .147$ & & & .342 / .338 & & & .157 / 154 & \\
\hline
\end{tabular}

Fixed Parts: Contrast against E. falciformis BayerHaberkorn 1970 (intercept; same random effects)

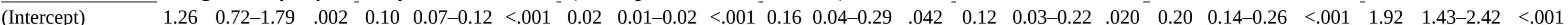

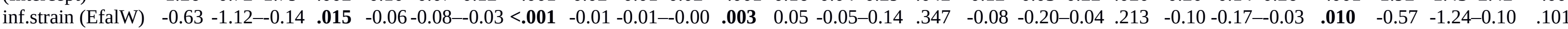

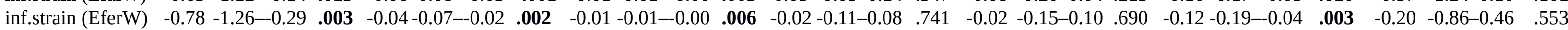

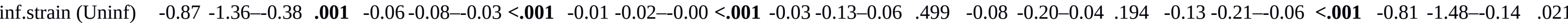




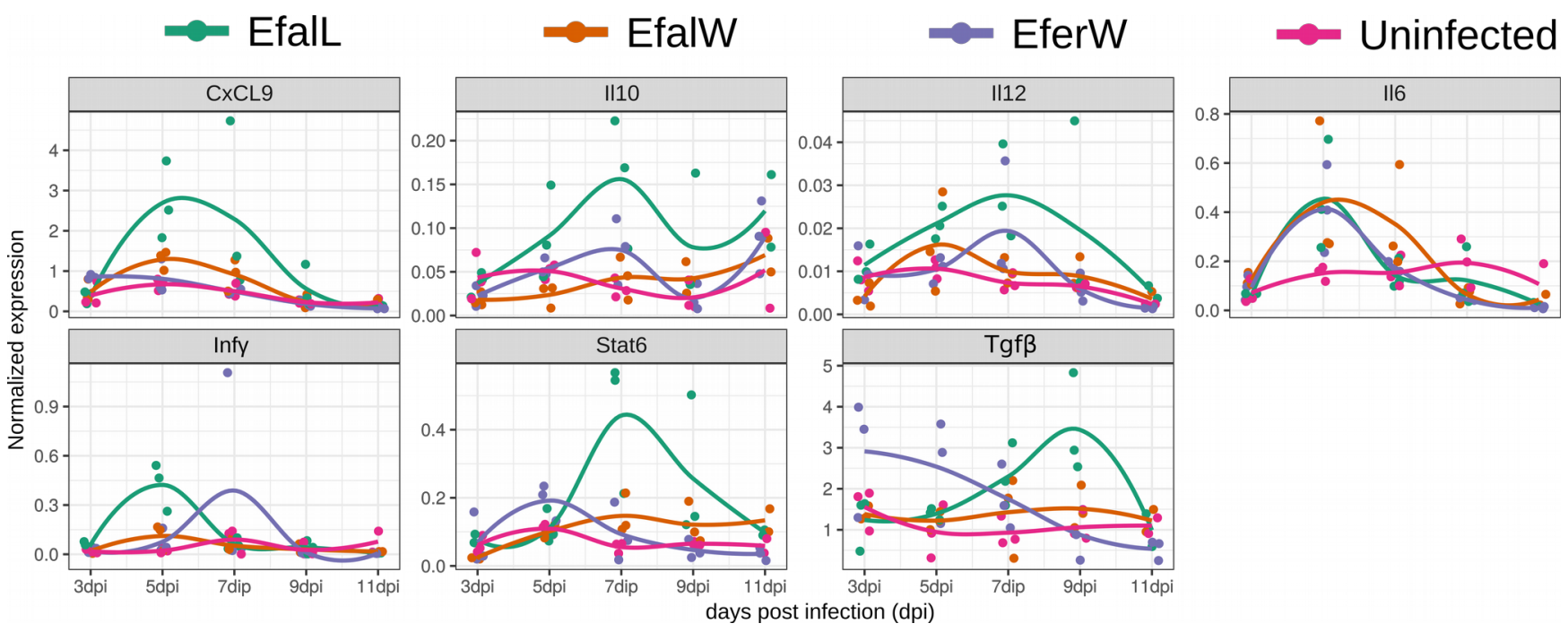

Figure 4 - Mice infected with a laboratory isolate of E. falciformis showed elevated gene expression in the spleen. Mice (NMRI) were infected with the wild derived isolate E. falciformis Brandenburg88 (EfalW), the laboratory isolate E. falciformis BayerHaberkorn1970 (EfalL), and the wild derived isolate E. ferrisi Brandenburg64 (EferW). Only E. falciformis BayerHaberkorn1970 induces mRNA expression in the spleen elevated over non-infected control and over mice infected with both wild derived isolates. Mice were sacrificed at different time points post infection (dpi) and mRNA expression levels were assessed using quantitative PCR. Dots indicate normalized expression values for individual mice. Lines are drawn using local polynomial regression fitting (a “loess smoother”).

\section{Inflammatory cell infiltration differs between Eimeria isolates}

To link our observation of gene expression in the spleen with independent measures of immune response and pathological changes, we performed a histological scoring of inflammatory cell infiltration (Table 2, Figure 5). Uninfected mice did not show inflammatory cell infiltration, besides a few $(n=2)$ exceptions with very low numbers of infiltrating lymphocytes.

In mice infected with the laboratory isolate E. falciformis BayerHaberkorn1970 a relatively high score of inflammation was observed during pre-patency as early as at $5 \mathrm{dpi}$. The extent of immune infiltration remained high until 9 dpi and declined towards 11 dpi. In contrast, in caeca of mice infected with the wild derived isolate E. falciformis Brandenburg 88, only low numbers of inflammatory cells were found during the pre-patent period. Infiltration consisted mainly of lymphocytes and plasma cells at this stage of infection. Inflammation then increased at $7 \mathrm{dpi}$, and during this period, eosinophilic granulocytes were also detected. Infiltration was strongest at 9 dpi in infections with this isolate before 
decreasing slightly towards $11 \mathrm{dpi}$. The quality of the infiltration was the same in infection with both wild derived and laboratory isolate of E. falciformis. Infiltrations are consistently characterised by lymphocytes, plasma cells and the presence of eosinophils (Figure 5).

In infections with E. ferrisi Brandenburg64 a milder inflammatory response was detected on 3 dpi and 5 dpi, with the latter being relatively stronger (compared to other dpi of E. ferrisi infection), followed by a subsequent decline towards 7 dpi.

We analysed the inflammation score of mice sacrificed at different dpi (Table 2) in mixed effect models using dpi as random factor. Overall inflammation was significantly lower in E. ferresi infected mice than in those infected with E. falciformis (glmm; E. ferrisi vs. E. falciformis BayerHaberkorn1970, p = 0.001; E. ferrisi vs. E. falciformis Brandenburg88, p = 0.014).

Table 2 - Score for the relative severity of leukocyte infiltration in histologic sections from the mid-part of the caecum from NMRI mice infected with Eimeria spp.

\begin{tabular}{|l|l|l|l|l|l|}
\hline \multirow{2}{*}{ Infection } & \multicolumn{5}{l|}{ Relative severity of leukocyte infiltration in caecum ${ }^{1}$} \\
\cline { 2 - 6 } & $3 \mathrm{dpi}$ & $5 \mathrm{dpi}$ & $7 \mathrm{dpi}$ & $9 \mathrm{dpi}$ & $11 \mathrm{dpi}$ \\
\hline \multirow{2}{*}{ E. ferrisi Brandenburg64 } & $2,1,1$ & $1,2,2$ & $1,2,1$ & $1,1,1$ & $0,0,0$ \\
\hline E. falciformis Brandnburg88 & $0,1,1$ & $1,0,1$ & $2,2,2$ & $3,2,3$ & 2,2 \\
\hline E. falciformis BayerHaberkorn1970 & $1,2,1$ & $3,3,3$ & $3,3,2$ & $3,3,2$ & 1,1 \\
\hline
\end{tabular}

${ }^{1}$ Leukocyte infiltration was scored on a 0 to 3 scale, where 0 represent no infiltration and 1,2 , 3 represented low, moderate, or high infiltration, respectively. One section from each caecum sample was used for scoring. Three fields of view (at 200-time magnification) were evaluated for the amount of inflammatory infiltrates and a numerical score was assigned by averaging over these fields. 
bioRxiv preprint doi: https://doi.org/10.1101/611277; this version posted May 17, 2019. The copyright holderfor this preprint (which was not certified by peer review) is the author/funder, who has granted bioRxiv a license to display the prepint in perpetuity it is made available under aCC-BY 4.0 International licen
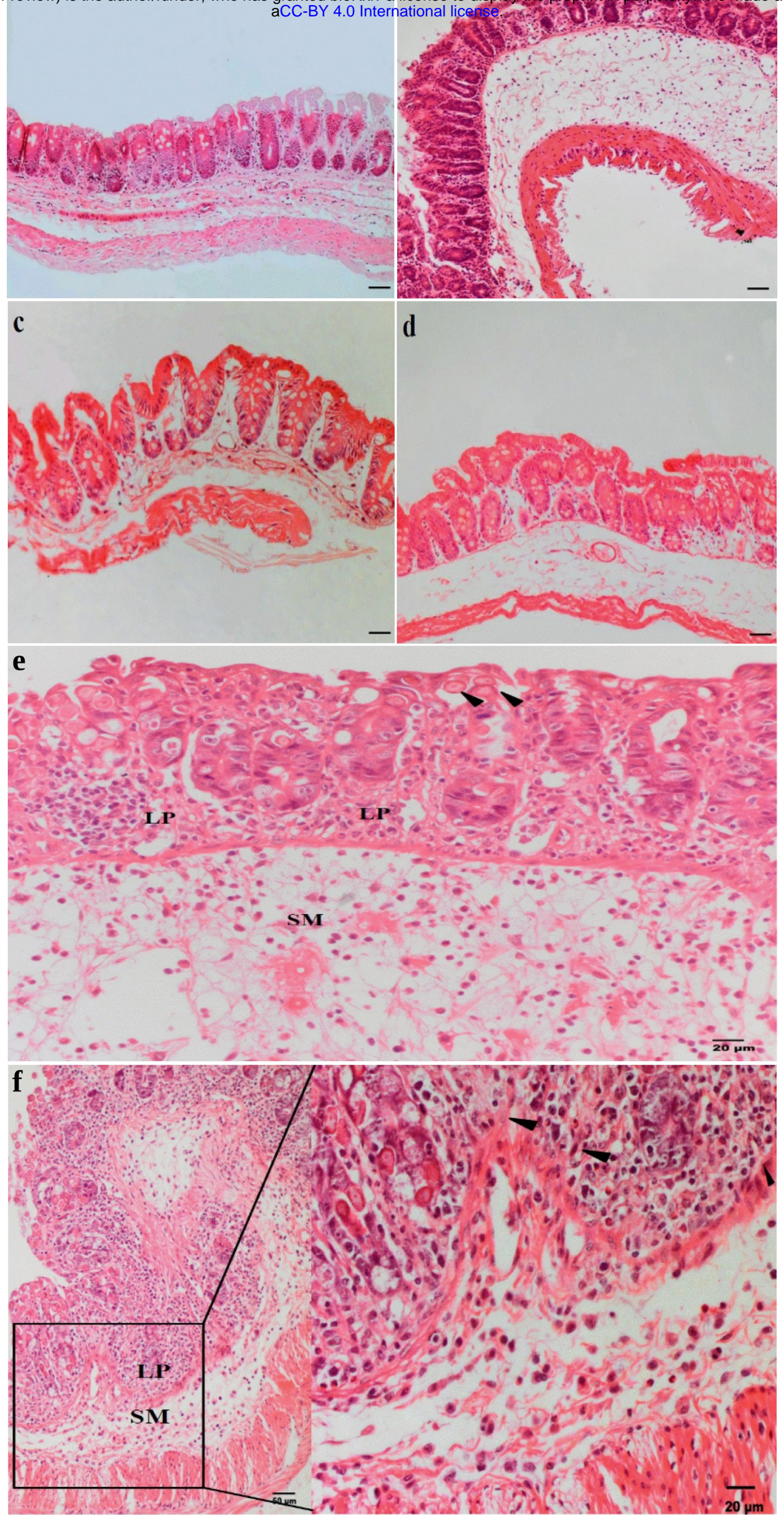
Figure 5 - Immune cell infiltration and parasites in histological caecum sections obtained from mice infected with different Eimeria isolates. NMRI mice were innoculated with 200 oocysts. a) Mice infected with the laboratory strain E. falciformis BayerHaberkorn1970 show moderate inflammation (score 2, Table 2) at $3 \mathrm{dpi}$ and strong inflammation b) at 5 dpi (score 3, Table 2). Infections with the wild derived isolate E. ferrisi Brandenburg64 at c) 3 dpi and d) 5 dpi, show low numbers of infiltrating immune cells (score 1, Table 2). Evident inflammatory process (score 3= high, Table 2) is associated with appearance of sexual stages and developing oocysts (black arrows) of the E. falciformis BayerHaberkorn1970 isolate at $7 \mathrm{dpi}$ (e) and the wild derived isolate E. falciformis Brandenburg88 at 9 dpi (f). The infiltrate consists mainly of lymphocytes and plasma cells. Note the high cellularity in the mucosa comprising lymphocytes in the lamina propria (LP) with fewer eosinophil and neutrophile in the LP and submucosa (SM). Scale bar 50 $\mu \mathrm{m}$ in a-d. 


\section{Discussion}

Infections are increasingly studied in combinations of natural systems and laboratory settings to understand the evolution of pathogens and the immune system. Natural parasites of the house mouse can play an important role when bridging this research with experimental immunology. We here study Eimeria spp., natural parasites of the house mouse. We evaluated whether the "laboratory isolate" E. falciformis BayerHaberkorn1970 (Haberkorn, 1970) differs from wild derived isolates of the same species and of E. ferrisi concerning infection dynamics, pathogenicity and the immune reactions it induces. We found not only expected differences in parasite life cycle progression between Eimeria species (E. falciformis vs. E. ferrisi), but also differences between the wild derived and laboratory isolate of E. falciformis. The laboratory isolate of E. falciformis induces relatively stronger immune reactions and pathologic changes in NMRI mice than newly derived isolates of both E. ferrisi and E. falciformis.

Between the two E. falciformis isolates BayerHaberkorn1970 and Brandenburg88 we observed only slight differences in the length of the pre-patent period (time until oocyst shedding, starting at 6 vs. 7 dpi). These results are in agreement with previous reports from the same host (NMRI mice) and the BayerHaberkorn1970 isolate (Stange et al., 2012; Schmid et al., 2012, 2014; Ehret et al., 2017). The pre-patent period for the wild derived E. falciformis isolate (7 dpi) corresponds to that reported for the parasite isolate E. falciformis var praghensis (Mesfin et al., 1978; Kasai et al., 1991), but Mahrt and Shi (1988) and Schito et al. (1996) demonstrated slightly longer pre-patent periods (7 or 8 dpi) also in other E. falciformis infections.

The output of oocysts in our study (for all isolates) was similar or only slightly lower than in previous reports (Schmid et al., 2014; Ehret et al., 2017). Our observation regarding the lifecycle progression of E. ferrisi, agree with the initial description of the life cycle in Mus musculus (Ankrom et al., 1975). E. ferrisi is characterized by a short life cycle - especially when compared to E. falciformis - with patency at $3 \mathrm{dpi}$. It is also noteworthy that the oocyst output of this species did not differ significantly when compared to that of both E. falciformis isolates (Figure 1). This data establishes E. ferrisi Brandenburg64 as a parasite isolate with low pathogenicity and high parasite reproduction. It invites comparisons of host-parasite interactions with more pathogenic isolates and could be an attractive alternative infection model with less impact on the host, i.e. allowing shorter experiments more compliant with welfare of host animals. 
Pathogenicity assessed by maximal weight loss during infections with E. falciformis was more severe in the present study compared to previous experiments (Schmid et al., 2012; Stange et al., 2012; Ehret et al., 2017). A potential reason for such a relatively high pathogenicity could - as in any experimental Eimeria infection - be an underestimation when adjusting the number of sporulated oocysts for the inoculum. As observed by Haberkorn (1970) higher dosed inocula lead to enhanced pathology, while the extent and timing of oocyst shedding are not impacted. Importantly, we here developed a method to assess the intensity of intestinal stages relative to the number host cells (host-parasite $\Delta \mathrm{Ct}$ ). This allows us to argue for the consistency of infectious doses: the tissue intensity attained by all three strains used in our experiment was not significantly different, and the tissue intensity of the two E. falciformis was very similar throughout the infection. We can conclude that we report results from a strong infection relative to previous studies, which was consistent between innocula of different strains.

This allows us to compare weight loss as an indication of pathogenicity between strains and to relate this to parasite reproduction: in E. falciformis infections maximal weight loss was observed at 9 dpi, while infections with E. ferrisi induced a significantly lower maximal weight loss at 5 dpi. These observations can be either due to fewer or faster cycles of asexual merogony of the parasite. Lines of poultry Eimeria with an abbreviated life cycle (so called “precocious lines”) show low oocyst output and are less pathogenic to their host (McDonald and Ballingall, 1983; Shirley and Bellatti, 1988; Shirley and Long, 1990; Shirley and Harvey, 2000). E. ferrisi, in contrast, attains substantial oocyst output, but shares low pathology with such precocious lines. This suggests that short phases of asexual expansion might be associated with low pathogenicity in Eimeria infections independent of total oocyst shedding. Parasite fitness for "naturally precocious" species of Eimeria might be high, while simultaneously host fitness is affected relatively little by infections. Short lifecycles of Eimeria might be associated with tolerance by the host.

Integrating weight loss dynamics with parasite lifecycle progression and comparing the two isolates of $E$. falciformis and that of $E$. ferrisi shows that $E$. ferrisi induces most weight loss before the peak of its oocyst shedding, while both E. falciformis isolates impact the host after the peak of their oocyst shedding (Figure 2). These differences suggest that mechanisms underlying pathogenesis might be different between the two parasite species. Histology indicates that weight loss coincides with immune cell influx in E. falciformis infections (Figure 5). This influx differed slightly in timing starting at 5 dpi in the E. falciformis laboratory isolate and $7 \mathrm{dpi}$ in the wild derived isolate. Such influx of immune cells into the tissue is an immuno-pathological reaction (Stange et al., 2012), which might cause damage to the host. As an alternative or additional cause of pathogenicity, sexual reproduction of $E$. 
falciformis might directly cause an exhaust of epithelial cell which burst when oocysts are released into the lumen (Kasai et al., 1991). Infections with E. ferrisi were characterised by yet lower immune cell infiltration and weight loss coincided with the peak abundance of endogenous stages at 3 dpi (Figure 2), indicating that parasite proliferation causes disease in host infected with this species.

Inflammatory cellular infiltrations within the mucosa during experimental infections with Eimeria have been observed in many host species including mice (Mesfin et al., 1978; Rose et al., 1992; Laurent et al., 2001; Gadde et al., 2009; Muñoz-Caro et al., 2016). Schmid et al. (2014) demonstrated by immunohistochemical analyses that E. falciformis infection in the caecum of NMRI mice leads to tissue infiltration with lymphocytes and macrophages. These changes are accompanied by elevated expression of Infy and the production of the major chemokines CxC subfamily at the site of infection. Inflammatory infiltrates were also slightly more prominent in our experiment in the laboratory isolate E. falciformis BayerHaberkorn1970 than in the closely related wild derived E. falciformis Brandenburg88 isolate. We thus asked whether systemic immune response differs between infections and studied this based on mRNA expression in the spleen. In spleens of mice infected with the laboratory isolate of $E$. falciformis we observed elevated mRNA levels of the pro-inflammatory Th1 cytokine Il12. The Il12/Ifny axis is crucial for the activation of cellular immune responses against intracellular parasites including Eimeria (Ovington and Smith, 1992; Rose et al., 1992; Lowenthal et al., 1997; Lillehoj, 1998; Chow et al., 2011; Schmid et al., 2014; Ehret et al., 2017). We did not detect Ifny significantly unregulated itself, as an elevated expression was only observed early after infection (at 3 dpi). We, however, observed significantly increased expression of the anti-inflammatory Th1 cytokines Il10 and Tgfß. IL10 could counteract IFNY and is also expressed in the spleen of Eimeriainfected chicken (Rothwell et al., 2000). Il10 expression in the spleen could be indicative for an attempt to balance inflammation during infection. A failure to establish this inflammatory balance can lead to pronounced inflammation and immunopathology (Inagaki-Ohara et al., 2006). In addition, we observed significantly elevated mRNA expression of Stat6 and the major regulatory chemokine CxCL9, which can be induced downstream of INFY and are involved in recruitment and activation of effector T lymphocytes in the spleen as well as in non-lymphoid organs such as intestine (Schmid et al., 2014).

Only a few studies have assessed systemic immune response via expression of cytokines in the spleen during Eimeria infections. Steinfelder et al. (2005) showed that T-cell proliferated in mesenteric lymph nodes of mice during a drug abbreviated infection with E. falciformis. Nevertheless splenocytes released IFNY and IL4 and likely contribute to the development of a systemic humoral response. In strongly infected mice this could lead to a systematic immunopathology. E. tenella antigen has been shown to induce IFN release of splenocytes in immunized chickens (Prowse and Pallister, 1989). 
Similarly, Byrnes et al., 1993 illustrated that splenic macrophages can produce IL1 and TNF $\alpha$ during the primary infection of E. tenella and E. maxima. The expression of Toll-like receptors (TLR3, TLR15), signal adaptor (MyD88) (Zhou et al., 2014) and IFNy (Rothwell et al., 2000) has been detected in the spleen of chickens as a response to infection with E. tenella. Taken together our data indicate a systemic immune response against E. falciformis BayerHaberkorn detectable in the spleen based on elevated mRNA levels of cytokines previously associated with in Eimeria infections.

Infection with the laboratory isolate of E. falciformis lead to significantly higher expression levels of cytokines in the spleen compared to both wild-derived isolates. In contrast, the wild derived isolates of E. falciformis and E. ferrisi did not induce significant expression changes over control levels in our mixed effect model analysis.

In spite of the overall non-significant changes, stints of elevated mRNA expression (failing to be significant in an analysis over different time points) seem plausible for Il6 in the spleen during infections with all three Eimeria isolates. IL6 is expressed during the initial stage of inflammation at the site of infection, where it has a role in stimulating the intestinal epithelial proliferation and repair after injury (Kuhn et al., 2014). It can be transported as a protein through the bloodstream to the liver and spleen (Heinrich et al., 1990), where it promotes specific differentiation of naïve CD4+ T cells (Rincón et al., 1997). In experimental infections of mice with E. falciformis marked induction of Il6 transcription between 5 and 7 dpi has been reported at the site of infection (Ehret et al., 2017). Enhanced expression in the spleen might suggest that the immune modulatory role of IL6 in the spleen during Eimeria infections could be augmented by elevated mRNA expression within this organ.

Similarly, Tgf $\beta$ mRNA expression levels seemed elevated in the spleen early during infection with $E$. ferrisi ( 3 and $5 \mathrm{dpi}$ ) and late in infections with the $E$. falciformis laboratory isolate (7 and 9 dpi; only in the latter significantly though). The simultaneous elevation of Il6 expression levels, may indicate the involvement of a Th17 pathway to control the infection events. Tgf $\beta$ and Il6 play crucial roles in the induction of IL17 expression from naïve CD4+ T cells of mouse (Sehrawat and Rouse, 2017; Korn et al., 2009). IL17 in turn contributes to both immunopathology and parasite restriction during infection with E. falciformis (Stange, 2013). These exceptions only underline the fact that a systemic immune response was hardly detectable, using gene expression in the spleen, in infections with wild derived Eimeria isolates.

The apparent differences in immune response of the wild derived and the laboratory isolate of $E$. falciformis invite speculation about their origin. Unfortunately, we do not know the infection phenotype 
(pathogenicity and induced immune reactions) of E. falciformis BayerHaberkorn1970 directly after its isolation. It is plausible, however, that the pathology before serial passaging resembled that observed for our wild derived isolate. The consequences of serial passaging could then be seen as the result of an accidental evolutionary experiment (Ebert, 1998).

Independent of the ultimate reasons for the difference in immunogenicity, we conclude that the infections with the laboratory isolate E. falciformis might not be representative for parasite-host interaction in their original ecological and evolutionary context. Eimeria is one of the most relevant parasites for wildlife immunology and, for representative infection experiments, we recommend to isolate strains of the parasite from the natural system with minimal prior passaging.

\section{Material and Methods}

\subsection{Isolation of E. falciformis Brandenburg88 and E. ferrisi Brandenburg64.}

The pure inocula of wild derived isolates of E. falciformis Brandenburg88 and E. ferrisi Brandenburg64 were produced by a single passage through NMRI mice preceding the reported experiment. Briefly, sporulated oocysts of Eimeria for each isolate were recovered from faecal samples obtained by trapping individual wild house mice in the federal state of Brandenburg (Germany). The last part of the full name of novel isolates corresponds to a running number used for mice caught during field sampling. The mouse yielding the isolate E. falciformis Brandenburg88 had been caught at 13.84 52.2678 DD, the mouse yielding E. ferrsi Brandenburg64 at 13.4642 52.4164 DD.

Isolates were identified through amplification and sequence comparison of three genetic markers (small ribosomal subunit 18S, Cytochrome c Oxidase I COI and Open Reading Frame 470 ORF470) using primers previously reported (Zhao and Duszynski, 2001; Kvičerová et al., 2008; Ogedengbe et al., 2011). Sequences were generated by LGC (Berlin) based on forward and reverse primes and resulting forward and reverse reads were merged to a consensus sequence. Sequences from E. falciformis Brandenburg88 (MH751942, MH755305, MH755336) and E. ferrisi Brandenburg64 (MH751927, MH777469, MH755326) were deposited in the NCBI Genbank.

From flotations of these faecal samples 300 and 600 oocysts for E. ferrisi Brandenburg64 and E. falciformis Brandenburg88, respectively, were inoculated into 16 weeks old female NMRI mice. All mice were reared individually in wire cages in isolation cabinets and provided with food and water ad libitum. The faeces from those mice were collected daily. Oocysts in faeces were harvested using flotation (see below). They were then placed in $2 \%$ potassium dichromate and incubated at $25{ }^{\circ} \mathrm{C}$ for 4 
days to permit oocyst sporulation. Sporulated oocysts were examined repeatedly under a light microscope and were then stored at $4{ }^{\circ} \mathrm{C}$ for about 1 month prior to use. The inoculum of E. falciformis BayerHaberkorn1970 was prepared simultaneously using the same protocol.

\subsection{Infection protocol, oocyst counting and sample collection}

60 female NMRI mice (10 to 12 weeks old) were randomly assigned to one of four groups, including a control group that was not inoculated. Oocyst concentrations were adjusted by counting the total number of oocysts in $10 \mu \mathrm{l}$, directly on a standard microscope slide. Using these inocula, 45 mice (15 per group) were inoculated via oral gavage with $0.1 \mathrm{ml}$ of inoculum containing a single dose of 200 sporulated oocysts.

Faeces were collected daily, weighted and stored in $2 \%$ solution of potassium dichromate. For flotation the faecal material was homogenized, centrifuged at $3175 \mathrm{~g}$ and the pellet was washed with distilled water. Oocysts were recovered from the sediment by 2 successive flotations in saturated $\mathrm{NaCl}$ solution each followed by washing. After the last washing $2 \mathrm{ml}$ PBS were added, the pellet was suspended and $10 \mu \mathrm{l}$ of the solution were loaded into a "Neubauer-improved chamber”. Oocysts were counted in eight grid squares. Then the number of oocysts per gram faeces was obtained according to the $(0.1 \mu \mathrm{l})$ volume of one grid square: Concentration (oocyst/g) = total \#of oocyst / \#squares counted * $10.000 \mathrm{ml}^{-}$ $1 * 2 m l / g$ (faeces).

During the 11 days of the experiment the body weight of mice was recorded. From each group three mice were sacrificed on 3, 5, 7, 9, and 11 dpi. Immediately after death the viscera were exonerated and spleen and caeca removed. Caecal contents were gently removed with physiological $\mathrm{NaCl}$ solution and the tissue was cut longitudinally into two pieces. One piece was transferred into a $1.5 \mathrm{ml}$ tube containing RNAlater ${ }^{\circledR}$ (Life Technologies; Carlsbad, USA) and stored for $4 \mathrm{~h}$ at $4^{\circ} \mathrm{C}$ before being transferred to $-20{ }^{\circ} \mathrm{C}$. The second piece of caecum tissue was fixed in $4 \%$ formalin and stored at room temperature for histological examination.

\subsection{Quantification of Eimeria load in caecum tissue}

Frozen caecum tissue was manually homogenized by grinding in liquid nitrogen. Genomic DNA was extracted using innu PREP DNA Mini Kit® (Analytik Jena; Jena, Germany) according to the manufacturer's protocol incorporating proteinase K digestion. Purified DNA was stored at $-20^{\circ} \mathrm{C}$.

A Mitochondrial COI fragment of Eimeria spp. was amplified using primers Eim-COI-forward 5’TGTCTATTCACTTGGGCTATTGT3' and Eim-COI-reverse 5’GGATCACCGTTAAATGAGGCA 3'. Host genomic DNA was amplified using a primer pair targeting the Mus-cdc42 gene: Mus-cdc42- 
forward

5’CTCTCCTCCCCTCTGTCTTG3’

and

Mus-cdc42-reverse

5’TCCTTTTGGGTTGAGTTTCC3’.

DNA samples were added for qPCR to Multiplate ${ }^{\mathrm{TM}}$ 96-Well PCR plates (BioRad; Hercules, USA), with reactions performed in duplicate for each sample. Each plate also contained a non template control and a plate control sample (ddH2O). The qPCR mixture was prepared using the $\mathrm{iQ}^{\mathrm{TM}}$ SYBR® Green PCR Kit (Bio-Rad; Hercules, USA): $5 \mu$ of $2 \mathrm{X}$ iQ ${ }^{\mathrm{TM}}$ SYBR ${ }^{\circledR}$ Green Master Mix, $0.3 \mu \mathrm{l}$ of $20 \mu \mathrm{M}$ forward and reverse primers, and $4 \mu \mathrm{l}$ of $10 \mathrm{ng} / \mu \mathrm{l}$ template DNA. The thermal cycling protocol was set as follows: initial denaturation for $15 \mathrm{~min}$ at $95^{\circ} \mathrm{C}$, followed by 40 cycles of $15 \mathrm{sec}$ at $95^{\circ} \mathrm{C}$, $30 \mathrm{sec}$ annealing at $60^{\circ} \mathrm{C}$ for Eim-COI primer or $58^{\circ} \mathrm{C}$ for $M u s-c d c 42$, and 30 sec at $68^{\circ} \mathrm{C}$ and measuring the fluorescence signal at the end of every step.

qPCR amplifications were performed using the Bio-Rad CFX96, Thermalcycler1000 system, which determined the cycle at threshold (Ct) fluorescence. To confirm the specificity of the assay a melting curve was generated after RT-PCR by adding a stepwise temperature increase from of $65.0^{\circ} \mathrm{C}$ to $95.0^{\circ} \mathrm{C}$, with $0.5^{\circ} \mathrm{C}$ increment. After calculating mean $\mathrm{Ct}$ of technical replicates, the abundance of Eimeria relative to host DNA was estimated as the $\Delta \mathrm{Ct}$ between mouse and parasite DNA. This is equivalent to a $\log (2)$-ratio between mouse host (Mus-cdc42) and Eimeria parasite (Eim-COI) DNA copies. The number of copies was calculated by taking the antilog for some examples in the text.

\subsection{RNA extractions and reverse transcription}

Frozen spleen tissue was homogenized by grinding in liquid nitrogen. Total RNA was isolated using the PureLink $^{\mathrm{TM}}$ RNA Mini Kit (Thermo Fisher Scientific; Waltham, USA). Briefly, frozen homogenized sample was transferred with a sterile scalpel blade into tubes with $1 \mathrm{ml}$ lysis solution with $1 \% 2$ Mercaptoethanol and $1.4 \mathrm{~mm}$ zirconium oxide beads (Peqlab GmbH, Erlangen, Germany). Samples were homogenized at room temperature using a Precellys ${ }^{\circledR} 24$ tissue homogenizer (VWR; Radnor, USA) twice at 6,000 rpm for $20 \mathrm{sec}$ interrupted by a $30 \mathrm{sec}$ cooling break. Samples were centrifuged for $1 \mathrm{~min}$ at maximum speed $(13,400 \mathrm{rpm})$ to eliminate foam. Supernatant was collected and mixed at a 1:1 ratio with $70 \%$ Ethanol. Afterwards, $600 \mu$ l of the mixture was added on a spin filter and centrifuged at 13,400 rpm for 30 sec. On-column DNase digestion was performed using PureLink DNase (Thermo Fisher Scientific, Waltham, USA) according to the manufacturer protocol. Column washing and elution was preformed as indicated by the manufacturer.

Synthesis of complementary DNA (cDNA) was performed using the RevertAid H Minus First Strand cDNA Synthesis Kit (Thermo Fisher Scientific, Waltham, USA) with engineered RevertAid ${ }^{\mathrm{TM}} \mathrm{H}$ Minus M-MuLV Reverse Transcriptase (200 U/ $\mu l)$. Nuclease-free water and $2 \mu$ l Oligo (dT)18 primers (100 
$\mu \mathrm{M}, 0.5 \mu \mathrm{g} / \mu \mathrm{l})$ were added to $1 \mu \mathrm{g}$ template RNA to a total volume of $22 \mu \mathrm{l}$. To denature potential secondary structures, the mixture was heated to $65^{\circ} \mathrm{C}$ for $5 \mathrm{~min}$ using the 2720 Thermal Cycler (Applied Biosystems; Foster City, USA) and rapidly cooled on ice afterwards to prevent renaturation.

Reverse transcription was carried out adding the reverse transcriptase mix and incubating for $60 \mathrm{~min}$ at $42^{\circ} \mathrm{C}$ followed by a termination at $70^{\circ} \mathrm{C}$ for $10 \mathrm{~min}$.

\subsection{Gene expression quantification}

We measured the mRNA expression levels of seven target genes: CxCL9, Il10, Il12, Tgfß, Stat6, Il6 and Infy. Cdc42, Ppia and Ppip were confirmed to be suitable as reference genes using 16 randomly selected cDNA samples in an analysis of mRNA expression stability (Axtner and Sommer, 2009; Weyrich et al., 2010) performed in qbase+ (Biogazelle; Zwijnaarde, Belgium) as implemented in the Bio-Rad CFX96 Thermalcycler1000. Respective primers are given in Table 3.

Table 3: Primer-pairs used for qPCR analysis of gene expression.

\begin{tabular}{|c|c|c|c|}
\hline Gene & Primer Sequence $\left(5^{\prime}-3^{\prime}\right)$ & Amplicon size(nt) & Source \\
\hline MmCDC42-F & СТСТССТССССТСТGTСTTG & 96 & This study \\
\hline MmCDC42-R & TCCTTTTGGGTTGAGTTTCC & & \\
\hline MmPpia-F & ACCGTGTTCTTCGACATCAC & 198 & This study \\
\hline MmPpia-R & ATGGCGTGTAAAGTCACCAC & & \\
\hline MmPpib-F & CAAAGACACCAATGGCTCAC & 161 & Ehret et al., 2017 \\
\hline MmPpib-R & TGACATCCTTCAGTGGCTTG & & \\
\hline MmIFNg-F & ACAGCAAGGCGAAAAAGGATG & 106 & Primer Bank \\
\hline MmIFNg-R & TGGTGGACCACTCGGATGA & & ID $145966741 c 2$ \\
\hline MmIL6-F & TAGTCCTTCCTACСССАATTTCC & 88 & Primer Bank \\
\hline MmIL6-R & TTGGTCCTTAGCCACTCCTTC & & ID 13624311a1 \\
\hline MmIL10-F & CCСATTCCTCGTCACGATCTC & 110 & Primer Bank \\
\hline MmIL10-R & TCAGACTGGTTTGGGATAGGTTT & & ID 6680389a1 \\
\hline MmIL12-F & ATGGCTGCTGCGTTGAGAA & 108 & Primer Bank \\
\hline MmIL12-R & AGCACTCATAGTCTGTCTTGGA & & ID 6680399a1 \\
\hline MmTGFb-F & TACGTCAGACATTCGGGAAGCAGT & 186 & This study \\
\hline MmTGFb-R & AAAGACAGCCACTCAGGCGTATCA & & \\
\hline MmCXCL9 & GGAGTTCGAGGAACCCTAGTG & 82 & Primer Bank \\
\hline MmCXCL9 & GGGATTTGTAGTGGATCGTGC & & ID $162287427 \mathrm{c} 1$ \\
\hline
\end{tabular}




\begin{tabular}{|l|l|l|l|}
\hline $\begin{array}{l}\text { MmSTAT6 } \\
\text { MmSTAT6 }\end{array}$ & CTCTGTGGGGCCTAATTTCCA & 135 & Primer Bank \\
ID 6678155a1
\end{tabular}

cDNA samples were split between PCR plates (Multiplate ${ }^{\mathrm{TM}}$ 96-Well, Bio-Rad; Hercules, USA) with reactions performed in duplicate for each sample. If the standard deviation of Ct values between duplicates was $>0.4$, reactions for corresponding samples were repeated (as described in Weyrich et al., 2010). Each plate contained a non-template control sample.

The qPCR mixture of $10 \mu \mathrm{l}$ was prepared using the iQ ${ }^{\mathrm{TM}}$ SYBR ${ }^{\circledR}$ Green PCR Kit (Bio-Rad): $5 \mu \mathrm{l}$ of $2 \mathrm{x}$ $\mathrm{iQ}^{\mathrm{TM}}$ SYBR ${ }^{\circledR}$ Green Master Mix, $3 \mu \mathrm{l}$ of $10 \mu \mathrm{M}$ forward and reverse primers, and $4 \mu \mathrm{l}$ of $10 \mathrm{ng} / \mu \mathrm{l}$ template cDNA. qPCR amplifications were performed using Bio-Rad CFX96, Thermalcycler1000 system as follows: initial denaturation for $15 \mathrm{~min}$ at $95^{\circ} \mathrm{C}$, followed by 40 cycles of 15 sec at $95{ }^{\circ} \mathrm{C}, 30$ sec at $60{ }^{\circ} \mathrm{C}$ and $30 \mathrm{sec}$ at $68{ }^{\circ} \mathrm{C}$ with a measuring of the fluorescence signal at the end of every step. The cycle of quantification (Ct) was determined by the amplification plot in CFX96-Bio-Rad software. Finally, a melting curve was generated to confirm the specificity of the reaction by adding a cycle of $65^{\circ} \mathrm{C}$ to $95^{\circ} \mathrm{C}$ in $0.5^{\circ} \mathrm{C}$ increments.

Normalization factors (NF) were calculated using the geometric mean of expression values for the three reference genes (Vandesompele et al., 2002). Relative expression values for each tested sample and each gene of interest were then calculated using the $\Delta \mathrm{Ct}$ method, adjusted for the amplification efficiencies of each primer pair and standardized against the NF of each sample.

\subsection{Histological examination and scoring}

Formalin fixed samples from the mid-part of the caeca were embedded in paraffin and sectioned with 4 $\mu \mathrm{m}$ thickness. Tissue slides were stained with hematoxylin and eosin and were examined at 100- 200and 400-times magnification by light microscopy. The extent and nature of leukocyte infiltration in the intestinal wall was assessed based on the morphological characteristic of each cell type. A numerical score was assigned with 0 representing no leukocyte infiltration and 1, 2, and 3 mild, moderate, or severe infiltration, respectively.

\subsection{Statistical analyses and visualisation}

All statistical analyses and visualisations were performed in R (R Development Core Team, 2008). The non-parametric Mann-Whitney U-test was used to assess differences in the distributions of weight loss or oocyst shedding. Linear mixed effect models (function "Imer" of the package lme4) were used to test 
for differences in gene expression. For each gene (as response variable) these models used the infecting Eimeria isolate as only fixed effect and the time of infection (dpi) as a random intercept. Similarly, linear mixed effect models for leukocyte infiltration score (as response variable) were used with infection isolate as fixed effect and dpi as a random intercept. For visualisations the package ggplot2 was used, including the default "loess" smoother as indicated in figure legends.

\section{Ethics statement}

All animal procedures in this investigation were performed according to the German Animal Protection Laws as directed and approved by the overseeing authority Landesamt für Gesundheit und Soziales (Berlin, Germany) under permit number H0098/04.

\section{Acknowledgements}

The authors thank Deborah Dymke and Jenny Jost for help during the infection experiment, Anke Schmidt and Doris Krumnow for excellent technical assistance in qPCR and histology, respectively.

\section{Funding}

This work was funded by the German Research Foundation (DFG) Grant [HE 7320/1-1] to EH and by the Leibniz Institute for Zoo and Wildlife research (IZW). EAK was supported by the Erasmus Mundus PEACE II program. VHJ is an associated student of GRK 2046 funded by the DFG.

\section{Bibliography}

Abolins, S., King, E.C., Lazarou, L., Weldon, L., Hughes, L., Drescher, P., Raynes, J.G., Hafalla, J.C.R., Viney, M.E., Riley, E.M., 2017. The comparative immunology of wild and laboratory mice, Mus musculus domesticus. Nat. Commun. 8, 14811. https://doi.org/10.1038/ncomms14811

Ankrom, S.L., Chobotar, B., Ernst, J.V., 1975. Life Cycle of Eimeria ferrisi Levine \& Ivens, 1965 in the Mouse, Mus musculus. J. Protozool. 22, 317-323. https://doi.org/10.1111/j.15507408.1975.tb05177.x

Axtner, J., Sommer, S., 2009. Validation of internal reference genes for quantitative real-time PCR in a non-model organism, the yellow-necked mouse, Apodemus flavicollis. BMC Res. Notes. 2 (1), 264. 
Barclay, V.C., Kennedy, D.A., Weaver, V.C., Sim, D., Lloyd-Smith, J.O., Read, A.F., 2014. The Effect of Immunodeficiency on the Evolution of Virulence: An Experimental Test with the Rodent Malaria Plasmodium chabaudi. Am. Nat. 184, S47-S57. https://doi.org/10.1086/676887.

Brake, D.A., Fedor, C.H., Werner, B.W., Miller, T.J., Taylor, R.L., Clare, R.A., 1997. Characterization of immune response to Eimeria tenella antigens in a natural immunity model with hosts which differ serologically at the B locus of the major histocompatibility complex. Infect. Immun. 65, $1204-1210$.

Burke, M.K., 2012. How does adaptation sweep through the genome? Insights from long-term selection experiments. Proc. Biol. Sci. 279, 5029-5038. https://doi.org/10.1098/rspb.2012.0799.

Byrnes, S., Eaton, R., Kogut, M., 1993. In vitro interleukin-1 and tumor necrosis factor-alpha production by macrophages from chickens infected with either Eimeria maxima or Eimeria tenella. Int. J. Parasitol. 23, 639-645.

Canning, E.U., Anwar, M., 1968. Studies on Meiotic Division in Coccidial and Malarial Parasites. J. Protozool. 15, 290-298. https://doi.org/10.1111/j.1550-7408.1968.tb02125.x

Chapman, H.D., Barta, J.R., Blake, D., Gruber, A., Jenkins, M., Smith, N.C., Suo, X., Tomley, F.M., 2013. A selective review of advances in coccidiosis research. Adv. Parasitol. 83, 93-171. https:// doi.org/10.1016/B978-0-12-407705-8.00002-1

Chow, Y.-P., Wan, K.-L., Blake, D.P., Tomley, F., Nathan, S., 2011. Immunogenic Eimeria tenella Glycosylphosphatidylinositol-Anchored Surface Antigens (SAGs) Induce Inflammatory Responses in Avian Macrophages. PLoS ONE 6. https://doi.org/10.1371/journal.,pone.0025233

Ebert, D., 1998. Experimental evolution of parasites. Science 282, 1432-1435.

Ehret, T., Spork, S., Dieterich, C., Lucius, R., Heitlinger, E., 2017. Dual RNA-seq reveals no plastic transcriptional response of the coccidian parasite Eimeria falciformis to host immune defenses. BMC Genomics 18, 686. https://doi.org/10.1186/s12864-017-4095-6.

Elena, S.F., and Lenski, R.E. 2003. Microbial Genetics: Evolution Experiments with Microorganisms: The Dynamics and Genetic Bases of Adaptation. Nature Reviews Genetics 4 (6): 457-69. https://doi.org/10.1038/nrg1088.

Farrell, A., Coleman, B. I., Benenati, B., Brown, K. M., Blader, I. J., Marth, G. T., \& Gubbels, M. J., 2014. Whole genome profiling of spontaneous and chemically induced mutations in Toxoplasma gondii. BMC genomics, 15(1), 354.

Gadde, U., Chapman, H.D., Rathinam, T.R., Erf, G.F., 2009. Acquisition of immunity to the protozoan parasite Eimeria adenoeides in turkey poults and the peripheral blood leukocyte response to a primary infection. Poult. Sci. 88, 2346-2352. https://doi.org/10.3382/ps.2009-00320 
Haberkorn, A., 1970. Die Entwicklung von Eimeria falciformis (Eimer 1870) in der weißen Maus (Mus musculus). Z. Für Parasitenkd. 34, 49-67. https://doi.org/10.1007/BF00629179

Hashimoto, K., Tanaka, T., Matsubayashi, M., Endo, K., Umemiya-Shirafuji, R., Matsui, T., Matsuo, T., 2014. Host specificity and in vivo infectivities of the mouse coccidian parasites Eimeria krijgsmanni. Acta Parasitol. 59, 337-342. https://doi.org/10.2478/s11686-014-0251-1.

Heinrich, P.C, Castell, J. V. and Andus, T., 1990. Interleukin-6 and the Acute Phase Response., Biochem. J. 265,3: 621-36.

Heitlinger, E., Spork, S., Lucius, R., Dieterich, C., 2014. The genome of Eimeria falciformis reduction and specialization in a single host apicomplexan parasite. BMC Genomics 15. https:// doi.org/10.1186/1471-2164-15-696.

Hnida, J.A., Duszynski, D.W., 1999. Cross-Transmission Studies with Eimeria arizonensis, E. arizonensis-like Oocysts and Eimeria langebarteli: Host Specificity at the Genus and Species Level within the Muridae. J. Parasitol. 85, 873-877. https://doi.org/10.2307/3285824

Inagaki-Ohara, K., Dewi, F.N., Hisaeda, H., Smith, A.L., Jimi, F., Miyahira, M., Abdel-Aleem, A.S.F., Horii, Y., Nawa, Y., 2006. Intestinal Intraepithelial Lymphocytes Sustain the Epithelial Barrier Function against Eimeria vermiformis Infection. Infect. Immun. 74, 5292-5301. https://doi.org/ 10.1128/IAI.02024-05.

Jarquín-Díaz, V.H., Balard A., Jost J., Kraft J., Dikmen, M.N., Kvičerová J., Heitlinger, E. 2019. Detection and quantification of house mouse Eimeria at the species level - challenges and solutions for the assessment of Coccidia in wildlife. BioRxiv 636662. https://doi.org/10.1101/636662

Kasai, N., Ogassawara, S., Baccaro, M.R., 1991. Morphobiology and pathogenicity of Eimeria falciformis var. pragensis Cerna, Seraud, Mehlhorn \& Scholtyseck, 1974 in mouse (Mus musculus). Rev. Bras. Biol. 51, 731-745.

Korn T., Bettelli E., Oukka M., Kuchroo V.K., 2009. IL-17 and Th17 Cells. Annu. Rev. Immuol. 27:1, 485-517.

Kuhn, K.A., Manieri, N.A., Liu, T.-C., Stappenbeck, T.S., 2014. IL-6 stimulates intestinal epithelial proliferation and repair after injury. PloS One 9, e114195. https://doi.org/10.1371/journal.,pone.0114195

Kvičerová, J., Pakandl, M., Hypša V., 2008. Phylogenetic Relationships among Eimeria Spp. (Apicomplexa, Eimeriidae) Infecting Rabbits: Evolutionary Significance of Biological and $\begin{array}{lllll}\text { Morphological } & \text { Features. } & \text { Parasitology } & 135 & \text { (4): }\end{array}$ https://doi.org/10.1017/S0031182007004106. 
Kvičerová, J., Hypša, V., 2013. Host-Parasite Incongruences in Rodent Eimeria Suggest Significant Role of Adaptation Rather than Cophylogeny in Maintenance of Host Specificity. PLoS ONE 8, e63601. https://doi.org/10.1371/journal.,pone.0063601

Laurent, F., Mancassola, R., Lacroix, S., Menezes, R., Naciri, M., 2001. Analysis of Chicken Mucosal Immune Response to Eimeria tenella and Eimeria maxima Infection by Quantitative Reverse Transcription-PCR. Infect. Immun. 69, 2527-2534. https://doi.org/10.1128/IAI.69.4.25272534.2001

Lillehoj, H.S., 1998. Role of T lymphocytes and cytokines in coccidiosis. Int. J. Parasitol. 28, 10711081. https://doi.org/10.1016/S0020-7519(98)00075-7

Lowenthal., J.W., York, J.J., O’neil, T.E., Rhodes, S., Prowse, S.J., Strom, A.D.G., Digby, M.R., 1997. In Vivo Effects of Chicken Interferon- $\gamma$ During Infection with Eimeria. J. Interferon Cytokine Res. 17, 551-558. https://doi.org/10.1089/jir.1997.17.551

Lucius, R., Loos-Frank B., Lane R.P., Poulin R., Roberts C. and Grencis R.K., 2018. The Biology of Parasites. Wiley-Blackwell.

Mackinnon, M.J., Read, A., 1999. Selection for high and low virulence in the malaria parasite. Proc. R.

Soc. Lond. B Biol. Sci. 266, 741-748. https://doi.org/10.1098/rspb.1999.0699

Mackinnon, M.J., Read, A.F., 2004. Immunity Promotes Virulence Evolution in a Malaria Model. PLOS Biol. 2, e230. https://doi.org/10.1371/journal.pbio.0020230

Mahrt, J.L., Shi, Y.F., 1988. Murine major histocompatibility complex and immune response to Eimeria falciformis. Infect. Immun. 56, 270-271.

McDonald, V., Ballingall, S., 1983. Further investigation of the pathogenicity, immunogenicity and stability of precocious Eimeria acervulina. Parasitology 86 (Pt 3), 361-369.

Mesfin, G.M., Bellamy, J.E., Stockdale, P.H., 1978. The pathological changes caused by Eimeria falciformis var pragensis in mice. Can. J. Comp. Med. 42, 496-510.

Molnár, K., Ostoros, G., Dunams-Morel, D., Rosenthal., B.M., 2012. Eimeria that infect fish are diverse and are related to, but distinct from, those that infect terrestrial vertebrates. Infect. Genet. Evol. J. Mol. Epidemiol. Evol. Genet. Infect. Dis. 12, 1810-1815. https://doi.org/10.1016/j.meegid.2012.06.017

Muñoz-Caro, T., Machado Ribeiro da Silva, L., Rentería-Solis, Z., Taubert, A., Hermosilla, C., 2016. Neutrophil extracellular traps in the intestinal mucosa of Eimeria-infected animals. Asian Pac. J. Trop. Biomed. 6, 301-307. https://doi.org/10.1016/j.apjtb.2016.01.001. 
Ogedengbe, JD., Hanner RH, Barta JR., 2011. DNA Barcoding Identifies Eimeria Species and Contributes to the Phylogenetics of Coccidian Parasites (Eimeriorina, Apicomplexa, Alveolata). Int. J. Parasitol. 41 (8): 843-50. https://doi.org/10.1016/j.ijpara.2011.03.007.

Ovington, K.S., Smith, N.C., 1992. Cytokines, free radicals and resistance to Eimeria. Parasitol. Today 8, 422-426. https://doi.org/10.1016/0169-4758(92)90196-9

Owen, D., 1975. Eimeria falciformis (Eimer, 1870) in specific pathogen free and gnotobiotic mice. Parasitology 71, 293-303.

Prowse, S.J., Pallister, J., 1989. Interferon Release as a Measure of the T-Cell Response to Coccidial Antigens in Chickens. Avian Pathol. 18,4: 619-30 https://doi.org/10.1080/03079458908418637.

Pogonka, T., Schelzke, K., Stange, J., Papadakis, K., Steinfelder, S., Liesenfeld, O., Lucius, R., 2010. CD8+ cells protect mice against reinfection with the intestinal parasite Eimeria falciformis. Microbes Infect. 12, 218-226. https://doi.org/10.1016/j.micinf.2009.12.005

R Development Core Team, 2008. R: A language and environment for statistical computing. R Foundation for Statistical Computing. Vienna, Austria.

Rincón, M., Anguita J., Nakamura T., Fikrig E., Flavell RA., 1997. Interleukin (IL)-6 Directs the Differentiation of IL-4-Producing CD4+ T Cells,” The Journal of Experimental Medicine 185, 3: 461-69.

Rose, M.E., Hesketh, P., Wakelin, D., 1992. Immune control of murine coccidiosis: CD4+ and CD8+ T lymphocytes contribute differentially in resistance to primary and secondary infections. Parasitology 105 ( Pt 3), 349-354.

Rothwell, L., Muir, W., Kaiser, P., 2000. Interferon-gamma is expressed in both gut and spleen during Eimeria tenella infection. Avian Pathol. J. WVPA 29, 333-342. https://doi.org/10.1080/03079450050118467

Schito, M.L., Barta, J.R., Chobotar, B., 1996. Comparison of Four Murine Eimeria Species in Immunocompetent and Immunodeficient Mice. J. Parasitol. 82, 255-262. https://doi.org/10.2307/3284157

Schmid, M., Heitlinger, E., Spork, S., Mollenkopf, H.-J., Lucius, R., Gupta, N., 2014. Eimeria falciformis infection of the mouse caecum identifies opposing roles of IFNy-regulated host pathways for the parasite development. Mucosal Immunol. 7, 969-982. https:/doi.org/10.1038/ mi.2013.115

Schmid, M., Lehmann, M.J., Lucius, R., Gupta, N., 2012. Apicomplexan parasite, Eimeria falciformis, co-opts host tryptophan catabolism for life cycle progression in mouse. J. Biol. Chem. 287, 20197-20207. https://doi.org/10.1074/jbc.M112.351999 
Sehrawat, S., Rouse, B.T., 2017. Interplay of Regulatory T Cell and Th17 Cells during Infectious Diseases in Humans and Animals. Front. Immunol. 8. https://doi.org/10.3389/fimmu.2017.00341

Shirley, M.W., Bellatti, M.A., 1988. Live attenuated coccidiosis vaccine: selection of a second precocious line of Eimeria maxima. Res. Vet. Sci. 44, 25-28.

Shirley, M.W., Harvey, D.A., 2000. A Genetic Linkage Map of the Apicomplexan Protozoan Parasite Eimeria tenella. Genome Res. 10, 1587-1593.

Shirley, M.W., Long, P.L., 1990. Control of coccidiosis in chickens: immunization with live vaccines. Coccidiosis Man Domest. Anim. 321-341.

Stange, J., 2013. Studies on host-pathogen interactions at mucosal barrier surfaces using the murine intestinal parasite Eimeria falciformis. Humboldt University, Berlin.

Stange, J., Hepworth, M.R., Rausch, S., Zajic, L., Kühl, A.A., Uyttenhove, C., Renauld, J.-C., Hartmann, S., Lucius, R., 2012. IL-22 mediates host defense against an intestinal intracellular parasite in the absence of IFN- $\gamma$ at the cost of Th17-driven immunopathology. J. Immunol. Baltim. Md 1950 188, 2410-8. https://doi.org/10.4049/jimmunol.1102062

Steinfelder, S., Lucius, R., Greif, G., Pogonka, T., 2005. Treatment of mice with the anticoccidial drug Toltrazuril does not interfere with the development of a specific cellular intestinal immune response to Eimeria falciformis. Parasitol. Res. 97, 458-465. https://doi.org/10.1007/s00436005-1464-X

Swaggerty, C.L., Genovese, K.J., He, H., Duke, S.E., Pevzner, I.Y., Kogut, M.H., 2011. Broiler breeders with an efficient innate immune response are more resistant to Eimeria tenella. Poult. Sci. 90, 1014-1019. https://doi.org/10.3382/ps.2010-01246

Weyrich A., Axtner J., Sommer S., 2010. Selection and validation of reference genes for real-time RTPCR studies in the non-model species Delomys sublineatus, an endemic Brazilian rodent. Biochem. Biophys. Res. Commun. 392 (2), 145-149

Vrba, V., Pakandl, M., 2015. Host specificity of turkey and chicken Eimeria: controlled crosstransmission studies and a phylogenetic view. Vet. Parasitol. 208, 118-124. https://doi.org/10.1016/j.vetpar.2015.01.017

Zhao, X., Duszynski, D.W., 2001. Phylogenetic Relationships among Rodent Eimeria Species Determined by Plastid ORF470 and Nuclear 18S RDNA Sequences. Int. J. Parasitol. 31 (7): 71519. https://doi.org/10.1016/S0020-7519(01)00136-9. 
bioRxiv preprint doi: https://doi.org/10.1101/611277; this version posted May 17, 2019. The copyright holder for this preprint (which was not certified by peer review) is the author/funder, who has granted bioRxiv a license to display the preprint in perpetuity. It is made available under aCC-BY 4.0 International license.

Zhou, Z., Hu, S., Wang, Z., Guo, Z., Qin, B., Nie, K., 2014. Expression of Chicken Toll-Like Receptors and Signal Adaptors in Spleen and Cecum of Young Chickens Infected with Eimeria tenella. J Integr Agric. 13 (4): 904-910. https://doi.org/10.1016/S2095-3119(13)60384-6 